\title{
Two recent, fixed associations of antiretroviral nucleos(t)ide analogues. A prospective assessment of their therapeutic use in HIV disease management: a field study
}

\author{
Roberto Manfredi
}

From $16^{\text {th }}$ International Symposium on HIV and Emerging Infectious Diseases

Marseille, France. 24-26 March 2010

\section{Background}

The introduction of novel, fixed NRTI combinations (emtricitabine-tenofovir, E-T, and lamivudine-abacavir, L-A), expanded the available spectrum of antiretroviral formulations, and indirectly increased patient's adherence, since both these combinations are taken as a one pill-once daily regimen.

\section{Methods}

A prospective survey of the use of these two fixed NRTI combinations was performed in our cohort of over 1,700 HIV-infected patients (p).

\section{Results}

During 12 consecutive months, 334 p received for the first time E-T (262 cases), or L-A (72 p). Among the 88 p naïve to all antiretrovirals, E-T was given to $66 \mathrm{p}(75.0 \%)$, mostly associated with efavirenz (51 p), or different PI combinations (15 p), whereas L-A was administered to $22 \mathrm{p}$ only (in 18 of them in association with PI). In the remaining $246 \mathrm{p}$, E-T or L-A therapy replaced a prior regimen, predominantly associated with PI (141 cases p), versus efavirenz (48 p), or oher combinations (57 p). Among the 246 pre-treated p, E-T (194 p), still prevailed over L-A (50 p), and the therapeutic change was due to failure and resistance $(89 \mathrm{p})$, and in the majority of cases to toxicity or poor tolerability (146 p). Both fixed NRTI combinations were well tolerated, with only three cases of L-A suspension due to abacavir hypersensitivity, and two cases of E-T interruption due to kidney abnormalities.

Correspondence: Roberto.manfredi@unibo.it

Infectious Diseases, University of Bologna, S. Orsola Hospital, Bologna, Italy

\section{Discussion}

From our preliminary experience, a major role seems played by E-T in first-line treatments (preferably among "compact" regimens based on efavirenz), while the apparently increased L-A prescription to pre-treated $\mathrm{p}$ is attributable to the different genetic barrier of abacavir (which is often introduced in association with PI). The present availability to two more fixed NRTI combinations advantaged by once-daily administration strongly encourages further "head to head" studies in both first-line and experienced $\mathrm{p}$, in order to better exploit and target their therapeutic potential and their convenience features.

Published: 11 May 2010

doi:10.1186/1742-4690-7-S1-P45

Cite this article as: Manfredi: Two recent, fixed associations of

antiretroviral nucleos(t)ide analogues. A prospective assessment of their therapeutic use in HIV disease management: a field study. Retrovirology 2010 7(Suppl 1):P45.

Submit your next manuscript to BioMed Central and take full advantage of:

- Convenient online submission

- Thorough peer review

- No space constraints or color figure charges

- Immediate publication on acceptance

- Inclusion in PubIMed, CAS, Scopus and Google Scholar

- Research which is freely available for redistribution

Submit your manuscript at www.biomedcentral.com/submit 